تأثير إضافة الايثانول إلى الكازولين المرصص على أداء محرك احتراق داخلي يعمل

بشمعة القاح القعا
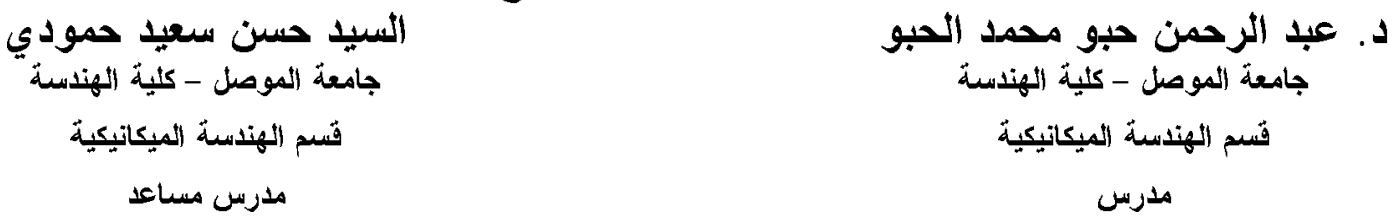

ألخلاصة

أجريت هذه الدراسة لمعرفة تأثير إضافة مسادة الايثانول بنقاوة 99.2\% إلى الكازولين المرصص على على أداء محرك

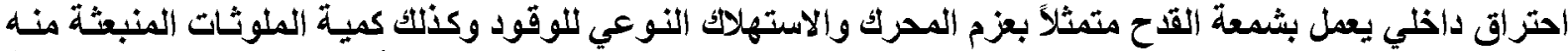

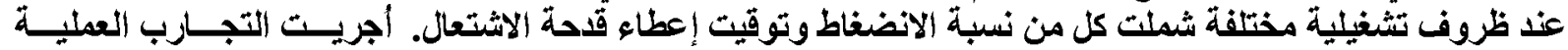

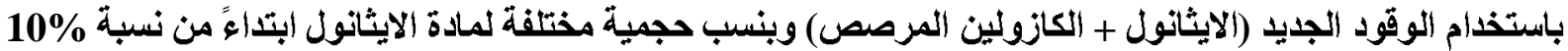

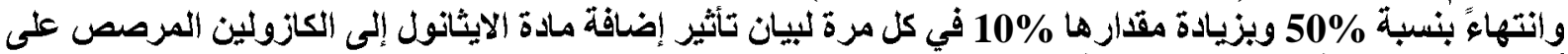
أداء المحرك وكمية الملوثثات المنبعثة منهئه

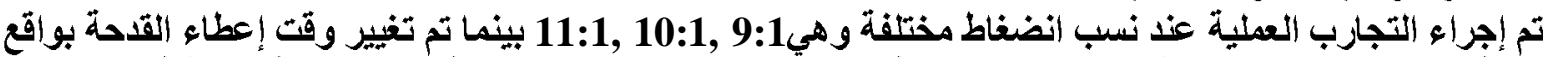

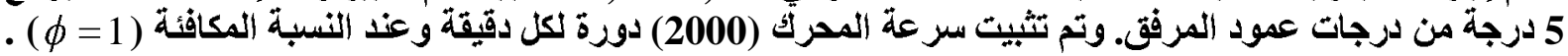

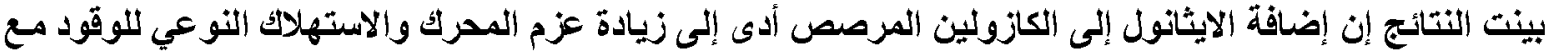

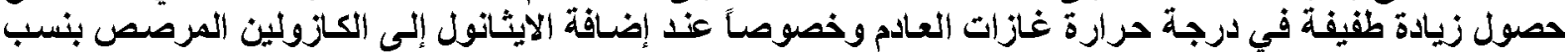

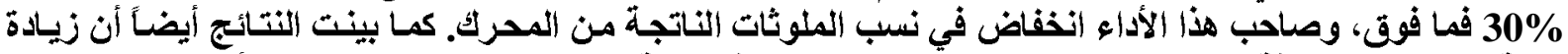

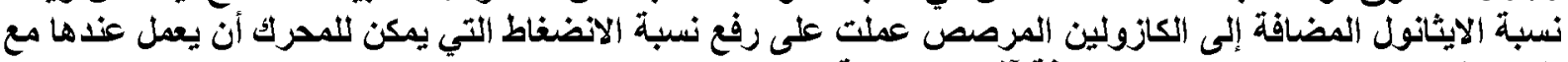

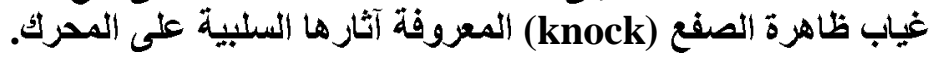

\title{
The Effect Of Adding Ethanol To leaded Gasoline on The Performance of Spark Ignition Engine
}

\author{
Dr. A.R Habbo \\ University of Mosul \\ College of Eng. \\ Mech. Eng. Dept
}

\author{
Mr.H.S Hammodi \\ University of Mosul \\ College of Eng. \\ Mech. Eng. Dept
}

\begin{abstract}
In this study the effect of adding pure ethanol (99.2\%) to leaded gasoline on the performance of spark ignition engine have been investigated. All tests were carried out using ethanol- leaded gasoline blends ( E10, E20, E30, E40 and E50) at various compression ratio ( 9:1, 10:1 and 11:1) for different ignition time ( $0^{\circ}$ TDC- $30^{\circ}$ BTDC), engine speed of $2000 \mathrm{rpm}$ and an equivalence ratio $(\phi=1)$.

The experimental results showed that blending leaded gasoline with ethanol slightly increased the torque, specific fuel consumption and exhaust gas temperature and in particular when E30, E40 and E50 blends are used. However, results also shows a significant reduction in exhaust emission for high percentage ethanol-gasoline blend, i.e for E30, E40 and E50. In addition to all that blending gasoline with ethanol allows engine to operate at high compression ratio without knock occurrence.
\end{abstract}

Keywords:- Spark ignition engine; Alternative fuel ; Exhaust emission 


\begin{tabular}{llll} 
Al-Rafidain Engineering & Vol.18 & No.4 & August 2010 \\
\hline
\end{tabular}

الرموز و المصطلحات العلمية

\begin{tabular}{|c|c|c|}
\hline الوحدة & التعريف & الرهز \\
\hline & شُبكة الاتصال الاصطناعي & ANN \\
\hline${ }^{\circ} \mathrm{CA}$ & بعد النقطة الميتة العليا & ATDC \\
\hline $\mathrm{g} / \mathrm{kW} \mathrm{h}$ & الاستهلاك النو عي الفرملي للوقود & BSFC \\
\hline \multirow[t]{10}{*}{${ }^{\circ} \mathrm{CA}$} & قبل النقطة الميتة العليا & BTDC \\
\hline & غازل أول أوكسيب الكاربون & $\mathrm{CO}$ \\
\hline & كحول الايثانول & $\mathrm{C}_{2} \mathrm{H}_{5} \mathrm{OH}$ \\
\hline & درجة من درجات عمود المرفق & ${ }^{\circ} \mathrm{CA}$ \\
\hline & الكازولين الخالي من أب إضافات & E0 \\
\hline & 90\% كازولين + 10\% إيثانول & E10 \\
\hline & 80\% كازولين + 20\% إيثانول & E20 \\
\hline & 70\% كازولين + 30\% إيثانول & E30 \\
\hline & 60\% كازولين + 40\% إيثانول & $\mathrm{E} 40$ \\
\hline & 50\% كازولين + 50\% إيثانول & E50 \\
\hline $\mathrm{kJ} / \mathrm{kg}$ & القيمة الحر ارية الواطنة للوقود & $\mathrm{LCV}$ \\
\hline N.m & القيمة العليا للعزم الفرملي & MBT \\
\hline $\mathrm{rpm}$ & النسر عة الدور انية للمحرك & $\mathrm{N}$ \\
\hline \multirow[t]{2}{*}{$\mathrm{kW}$} & القدرة الفزرلية & $\mathrm{Pb}$ \\
\hline & الوزن النوعي للوقود & $\mathrm{Sg}_{\mathrm{f}}$ \\
\hline N.m & عزم الهحرك & $\mathrm{T}$ \\
\hline Sec. & الز من & $\mathrm{t}$ \\
\hline \multirow[t]{6}{*}{${ }^{\circ} \mathrm{CA}$} & النقطة الميتة العليا & TDC \\
\hline & مادة رباعي أُثيل الرصاص & TEL \\
\hline & الهيدروكاربونات غير المحترقة & $\mathrm{UHC}$ \\
\hline & فتحة كبيرة للخانق & WOT \\
\hline & $\phi=(\mathrm{A} / \mathrm{F}) \mathrm{st} /(\mathrm{A} / \mathrm{F})$ act. & $\phi$ \\
\hline & نسبة الوقود إلى الهو اء النسبية . & $\lambda$ \\
\hline
\end{tabular}

المقدمة

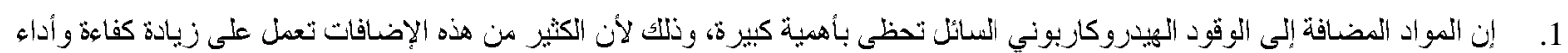

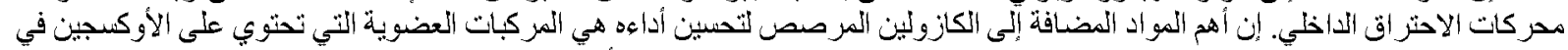

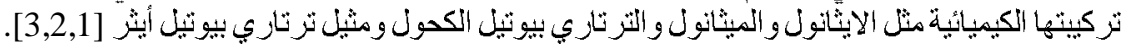

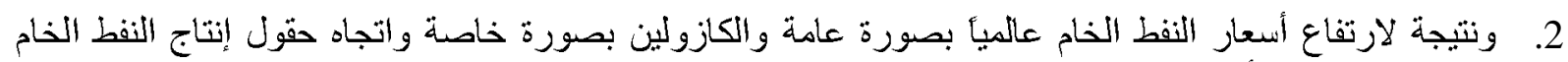

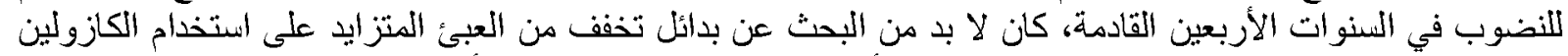

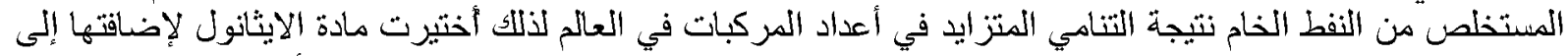

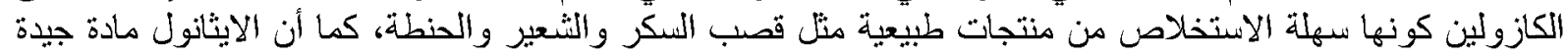

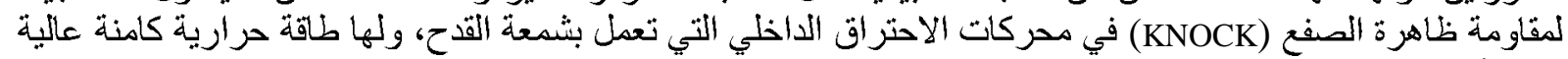

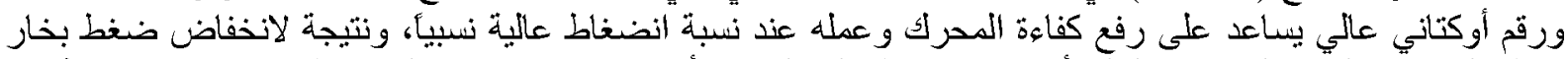

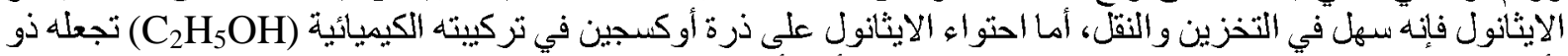

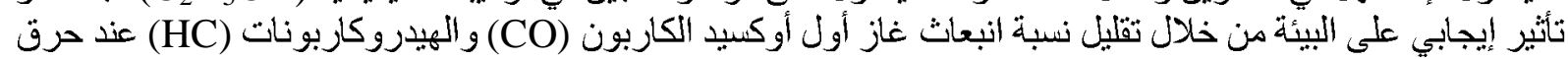

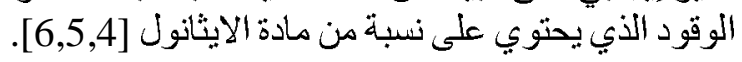

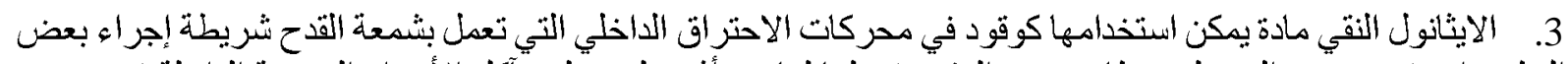

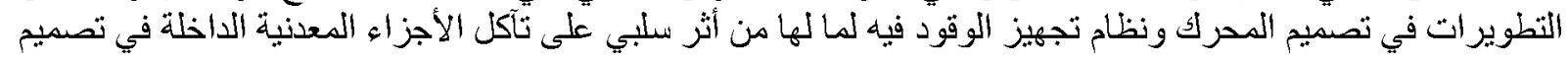


المحرك، وكذلك لما تسببه من تضيق وانسدادات في مجاري المقود داخل المبخرة، لذللك من الممكن استخدام الايثانول كمادة

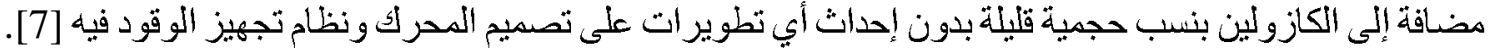

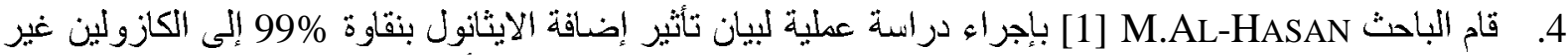

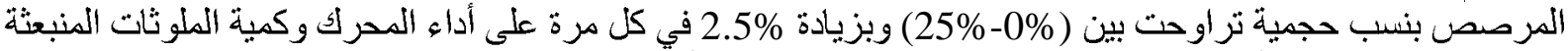

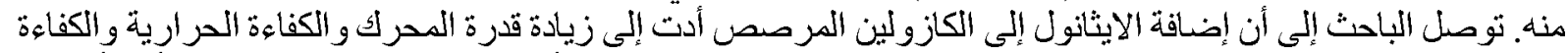

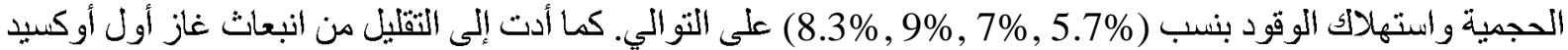
بنسب و والهيدروكاربونات

(46.5\%, 24.3\%) على التو الي من جهة، و إلى زيادة انبعاث غاز ثاني أوكسيد الكاربون بنسبة 7.5 من جهة أخرى.

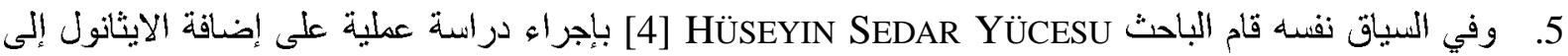

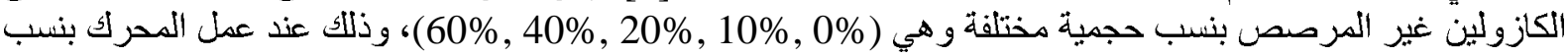

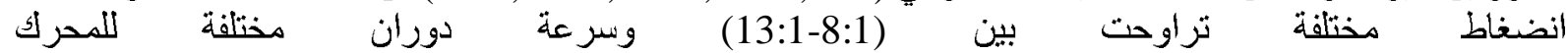

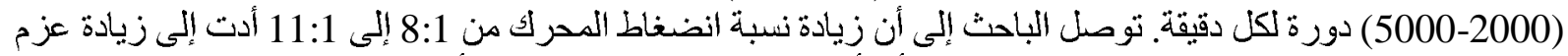

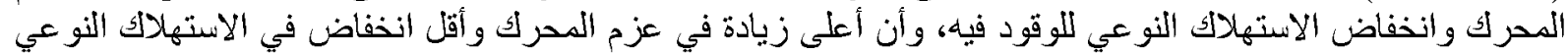

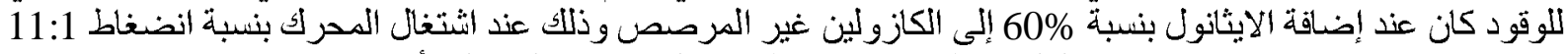

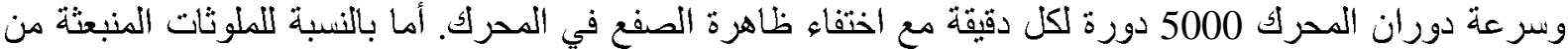

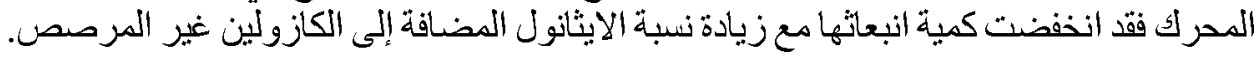

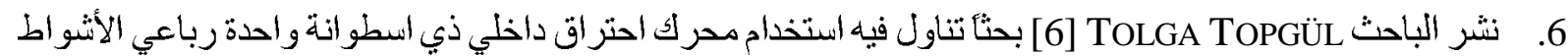

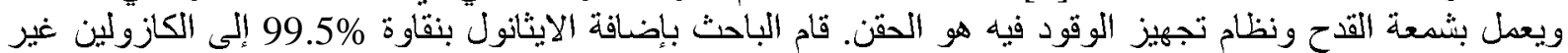
المرصص بنسب حجمية مختلفة هي (60\%, 40\%, 20\%, 10\%, 0\% بانتخدام متغير ات مختلفة و هي نسبة انضغاط

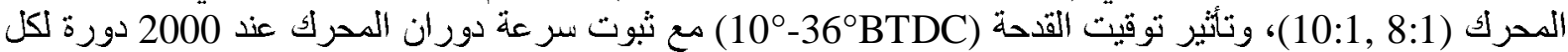

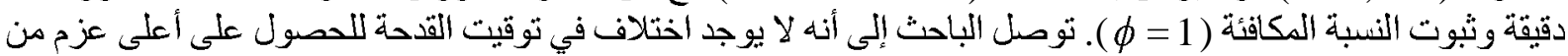

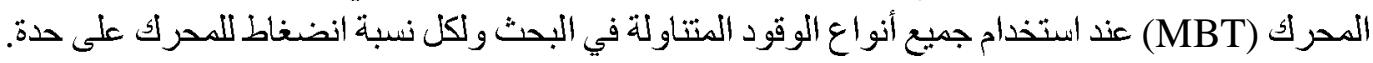

7. قام الباحث HAKAN B AYRABTAR [7 بإجر أه دراسة نظرية و عملية لبيان تأثير إضافة الايثانول إلى الكازولين غير

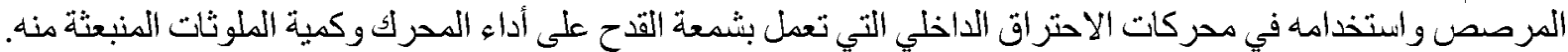

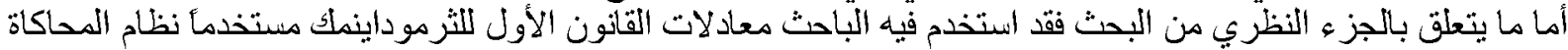
في تمثيل الاحتر اق وتقدم اللهب داخل غن فر فئة الاحتر اق.

8. أما الجز ء العملي من البحث فقد استخدم الباحث كحول الايثانول بنقاوة 93\% مادة مضافة إلى الكازولين غير المرصص

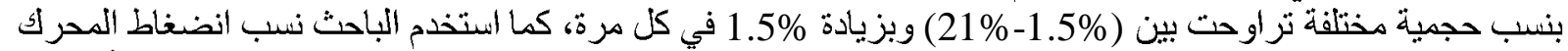

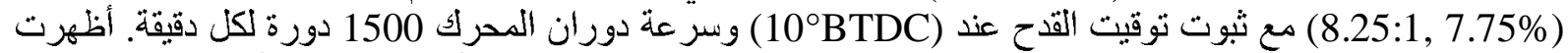

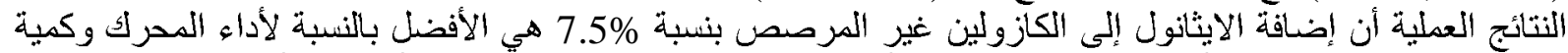

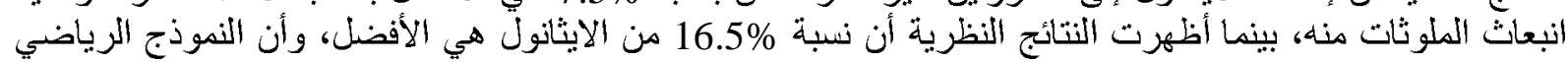

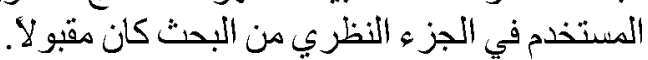

9. نشر الباحث HÜSEYIN SEDAR YÜCESU [8 بحثا تتاول فيه دراسة نظرية و عملية لاستخدام الايثانول مادة مضافة

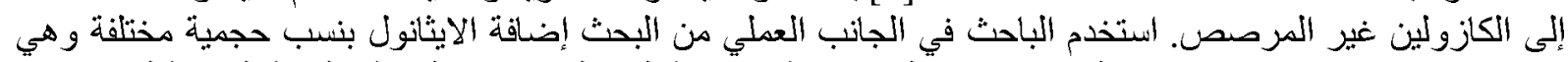

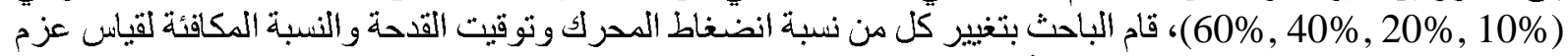
المحرك والاستهلاك النوعي للوقود فيه. أما الجانب النظري من البحث فقد اعتمد الباحث فيه على نظام التحليل العددي

$(\mathrm{ANN})$

(ARTIFICIAL NEURALNETWORK)

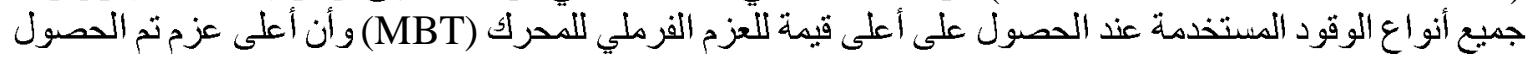

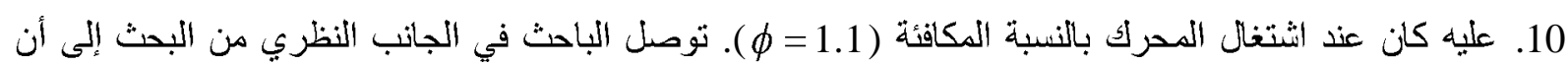
استخدام نظام (ANN) هو الأفضل لدر استة أداء الهحرك نظرياً.

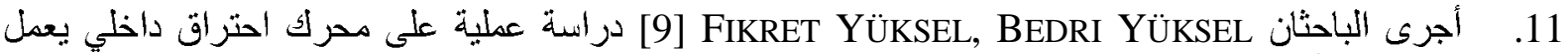
بثُمعات القدح ذي أربع اسطوانات ونسبة انضغاط 8:1 ونظام تجهيز الوقود إلى غرفة الاحتراق هو المبخرة. قام الباحثان 


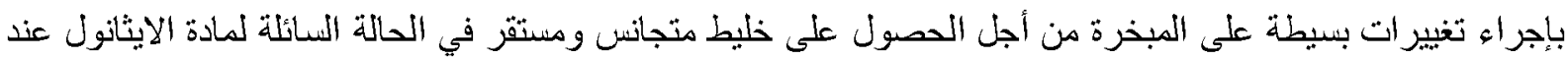

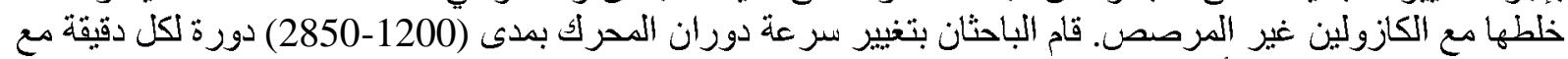
تغيير فتحة الخانق للمبخرة أربع مرات هين

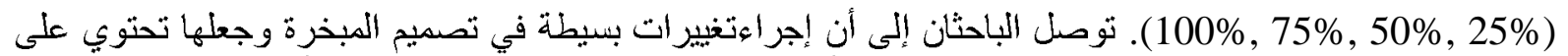

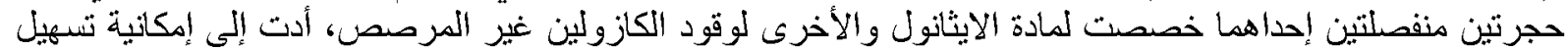
تثغيل المحرك بانتخدام نسب عالية من الايثانون إلى حد

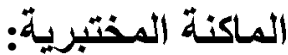

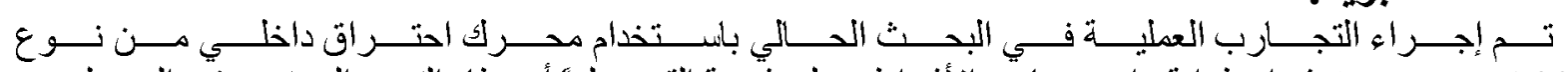

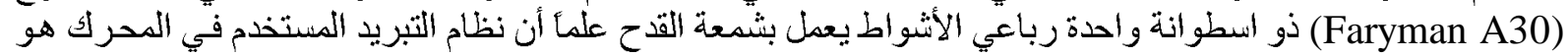

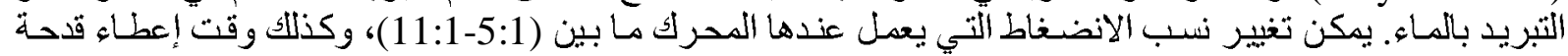

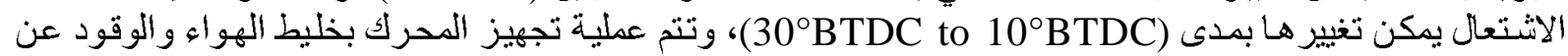
طريق المبخرة (carburator). لاحظ الثنكل (1).

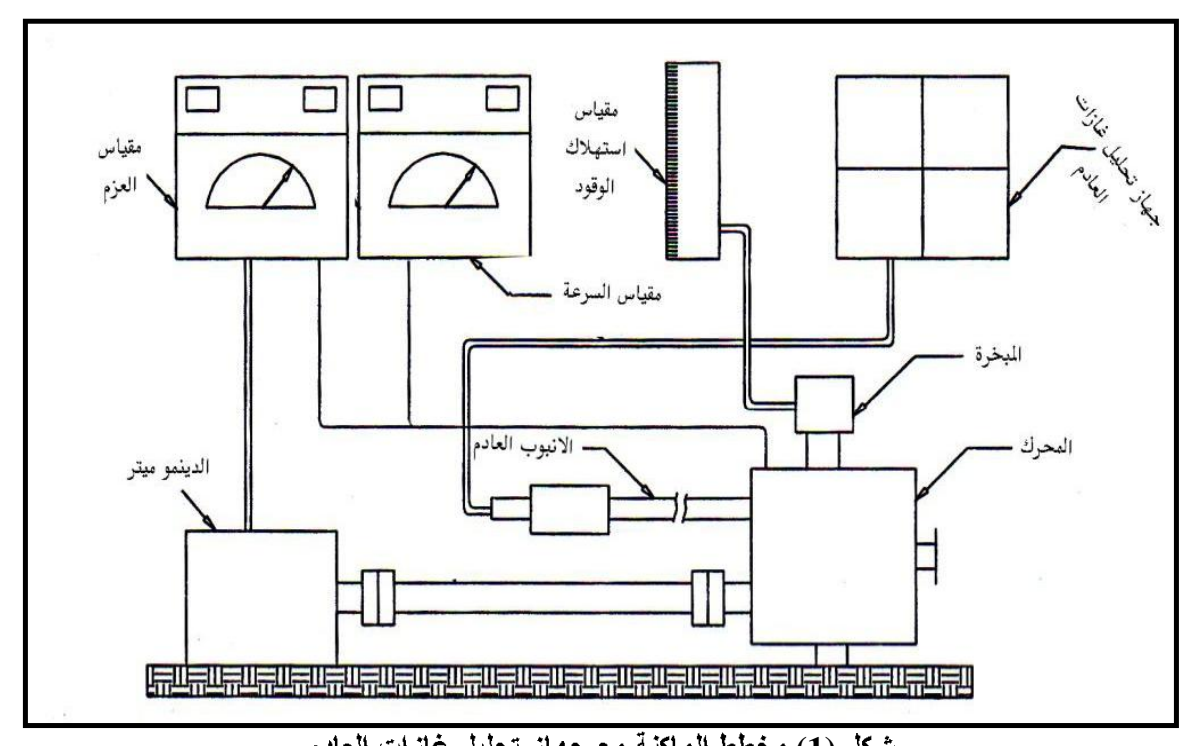

شكل (1) مخطط الماكنة مع جهاز تحليل غازات الثعادم

\section{لاحظ الجدول (1) الذي يمثل مواصفات الماكنة المختبرية المستخدمة في البحث الحالي.}

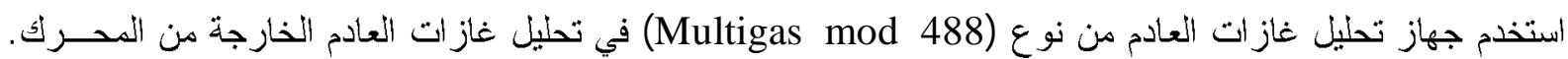

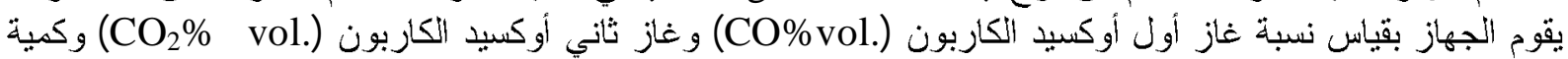

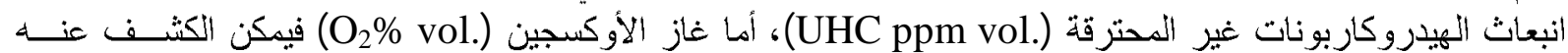
عن طريق متحس كيميائي. يقوم الجهاز بتحديد نسبة الوقود إلى الهو اء النسبية (

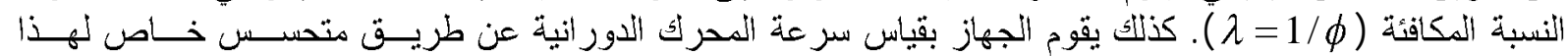

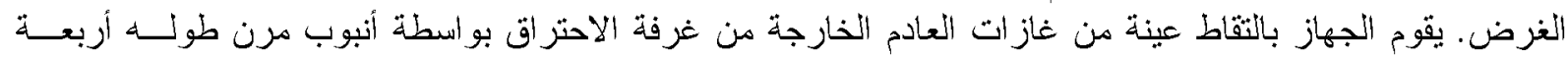

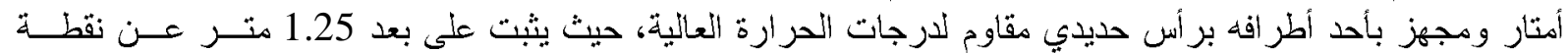
خروج غاز ات العادم من غرفة الاحتر اق فراق 


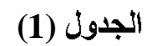

المواصفات العامة للماكنة المختبرية المستخدمة المخدة

\begin{tabular}{|l|l|l|l|}
\hline \multicolumn{1}{|c|}{ Item } & \multicolumn{1}{|c|}{ Specification } & \multicolumn{1}{c|}{ Item } & \multicolumn{1}{c|}{ Specification } \\
\hline Engine type & $\begin{array}{l}\text { Faryman A30 marine } \\
\text { diesel engine }\end{array}$ & Ignition timing (petrol) & $\begin{array}{l}30^{\circ} \text { BTDC } \\
10^{\circ} \text { ATDC }\end{array}$ \\
\hline Number of cylinder & 1 & Compression ratio & $5: 1$ to $18: 1$ \\
\hline Cylinder bore & $95 \mathrm{~mm}$ & Fuel system (petrol) & Carburetor \\
\hline Stroke & $82 \mathrm{~mm}$ & Fuel system (diesel) & Fuel enjection \\
\hline Cycle & $4-$ stroke & Cooling system & Water-coold \\
\hline Swept volume & $582 \mathrm{~cm}^{3}$ & Engine oil (sump) & 2 liters \\
\hline Speed range & 1000 to 2500 rev/min & Fuel tanks & 10 liters \\
\hline Maximum power & $7 \mathrm{Kw}$ & Cooling water reservoir & 1 liter \\
\hline Maximum torque & $50 \mathrm{~N} . \mathrm{m}$ & Ignition timing (petrol) & $30^{\circ} \mathrm{BTDC}$ \\
& & & $10^{\circ} \mathrm{ATDC}$ \\
\hline
\end{tabular}

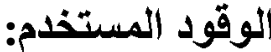

تتاول البحث الحالي تأثير إضافة الايثانول ذو النقاوة

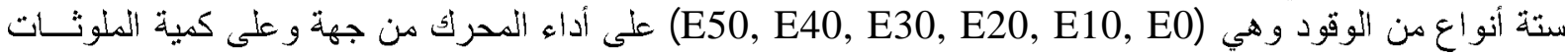

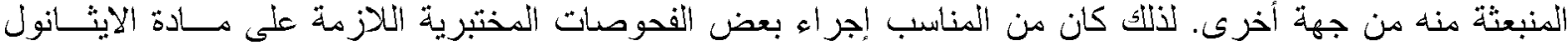

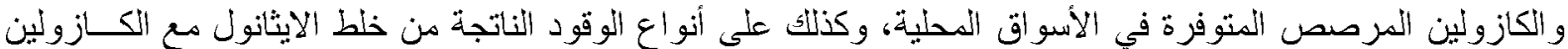

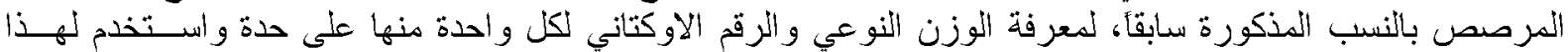

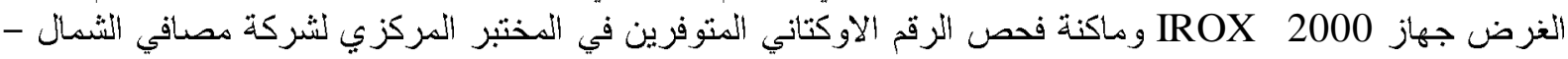

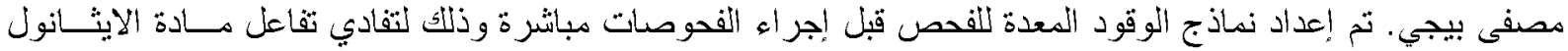

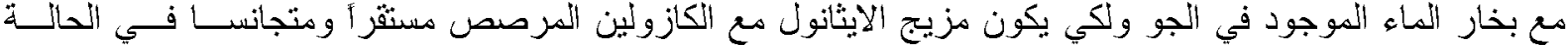

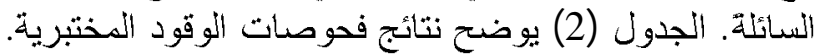

الجدول (2) نتائج فحص الوقود المختبرية

\begin{tabular}{|c|c|c|c|c|c|c|}
\hline & \multicolumn{6}{|c|}{ Fuel Type } \\
\cline { 2 - 7 } & E0 & E10 & E20 & E30 & E40 & E50 \\
\hline SPG $_{\text {f }}$ & 0.7282 & 0.7318 & 0.7378 & 0.7459 & 0.7469 & 0.7583 \\
\hline RON $^{2}$ & 76 & 83 & 89 & 95 & 99 & 101 \\
\hline
\end{tabular}

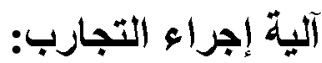

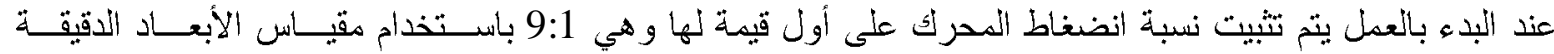
(Micrometer)

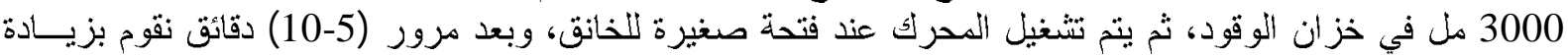

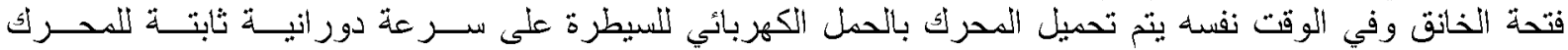

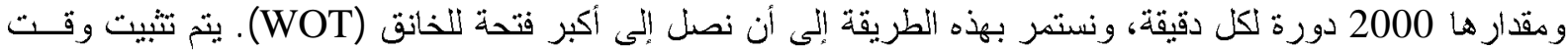

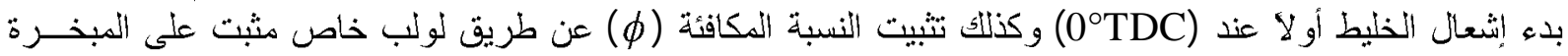

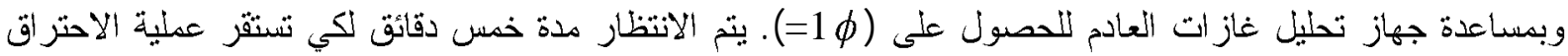

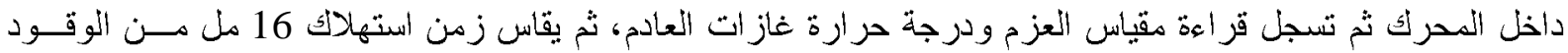

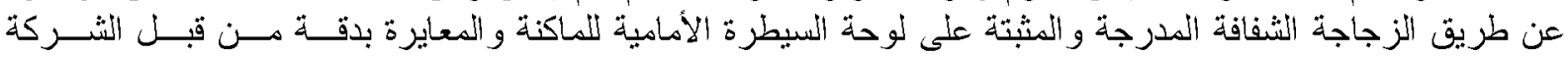

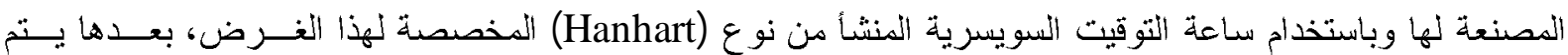

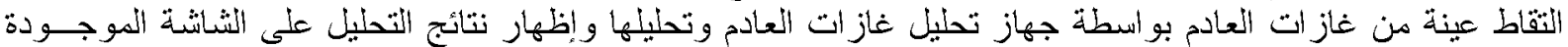
في الجهاز ثم يمكن طباعتها عن طريق طابعة مخصصة لهذا الغرض. يتم تسجيل قراءة جهاز تحليل غاز ات العادئ العادم في 


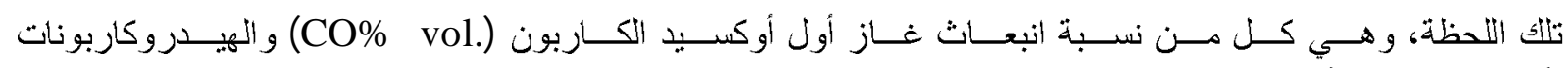
(HC ppm vol.)

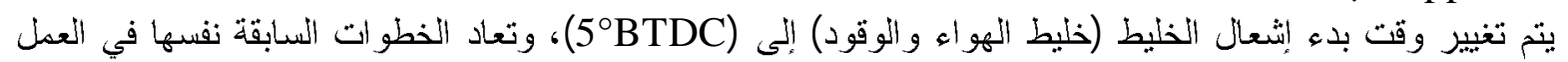

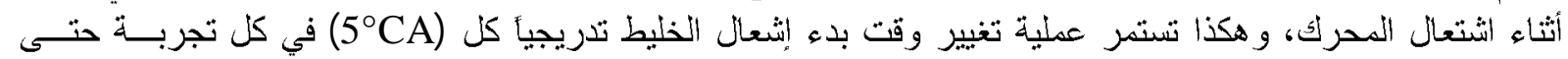

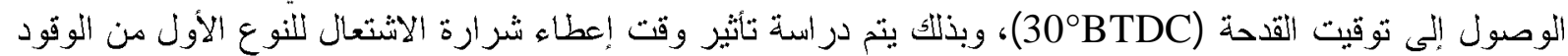

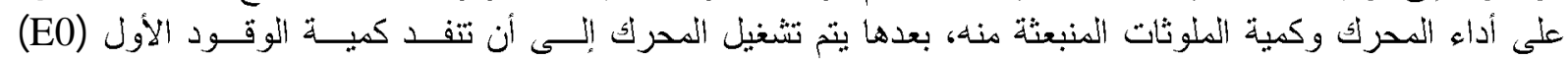

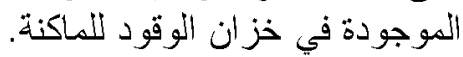

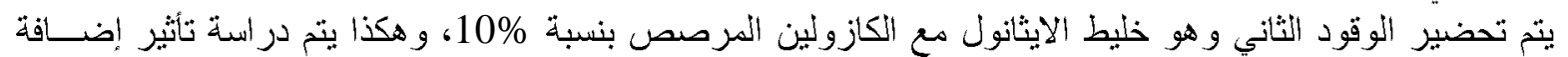

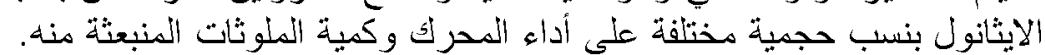

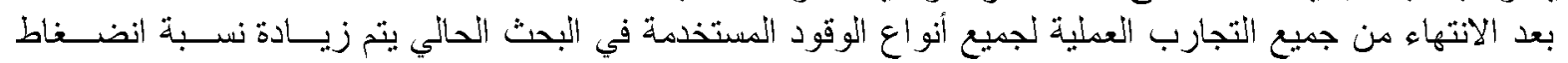

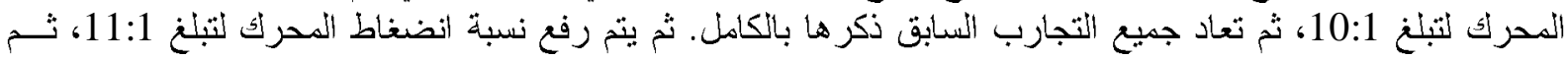
تعاد جميع التجارب السابق ذكرها بالكامل.

\section{النتانتج ومناقشتها:}

1. بينت النتائج التي تم الحصول عليها أن توقيت إعطاء شرارة القدح) (SPARK TIMING) ذو تأثير واضح وفعال على أداء

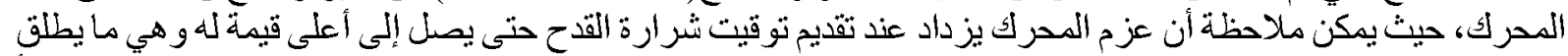

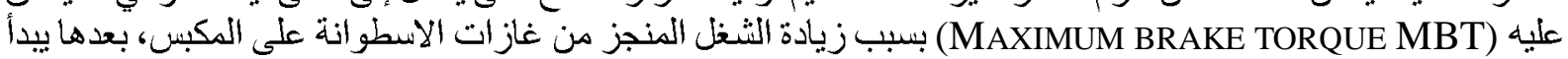
بالانخفاض عند استمرار زيادة تقديم توقيت القدحة.

2. تمثل الأثكال (4,3,2) العلاقة بين عزم المحرك وتوقيث الشرارة وذلاتك عند تشغيل المحرك بنسب انضغاط

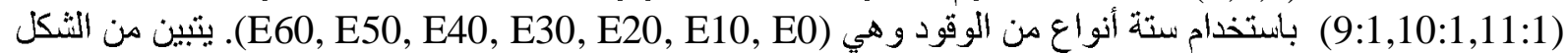

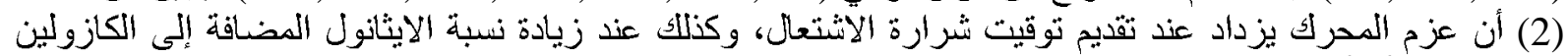

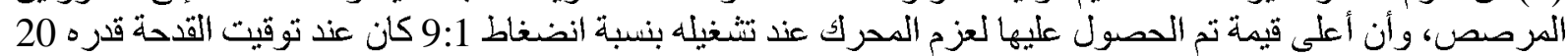

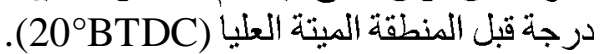

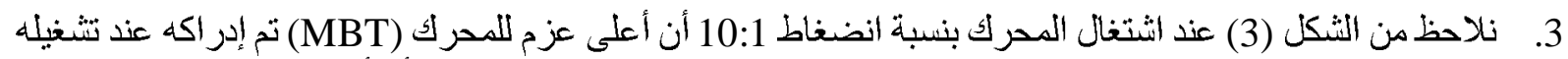

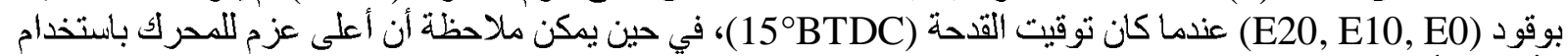

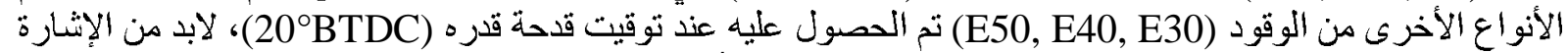

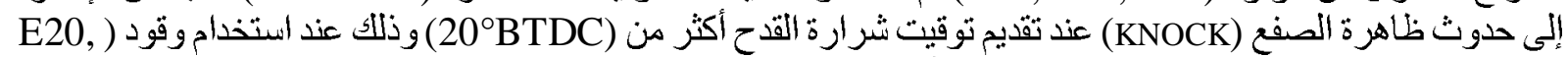

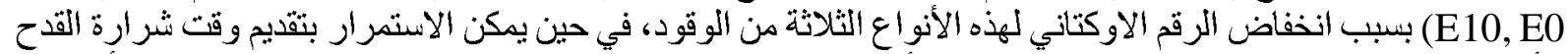

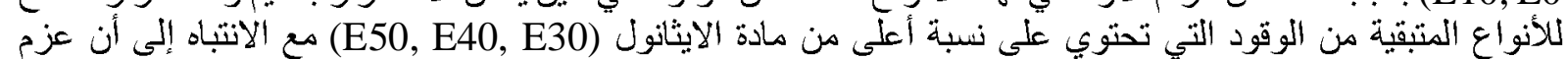

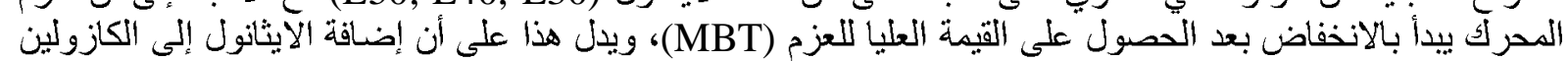

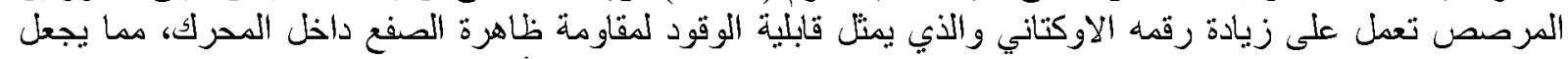

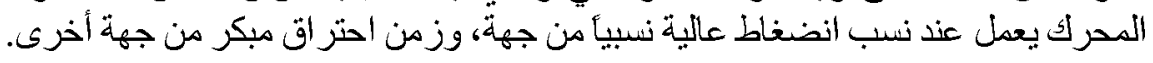

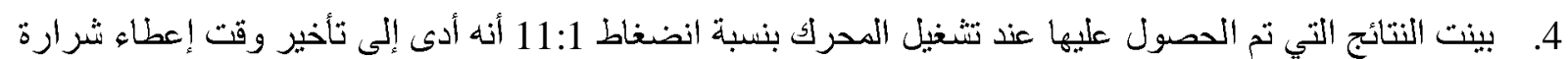

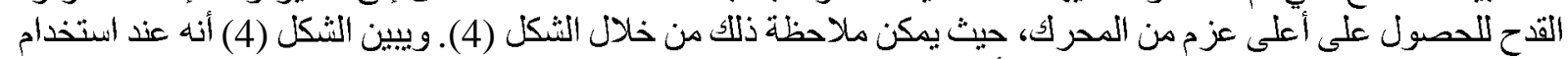

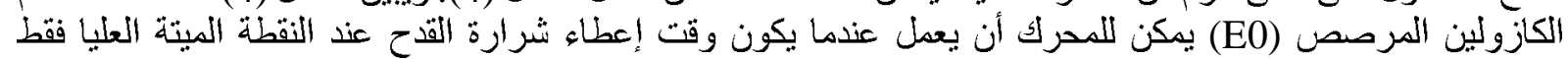
(OTDC)

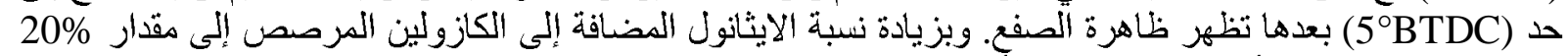

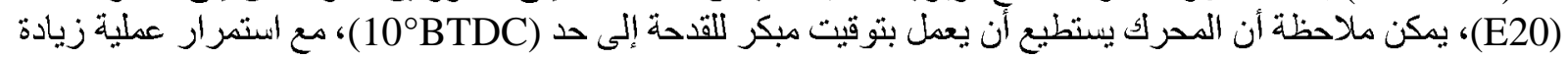

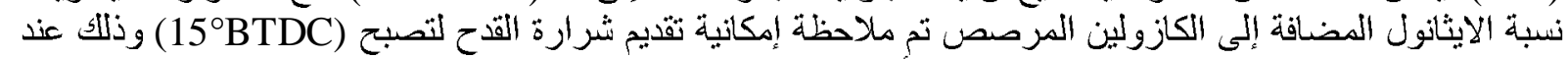

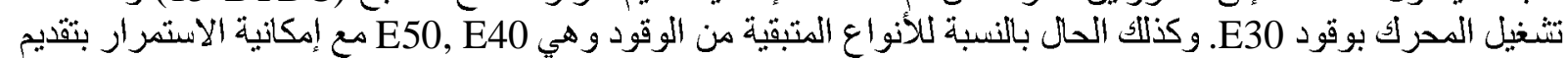

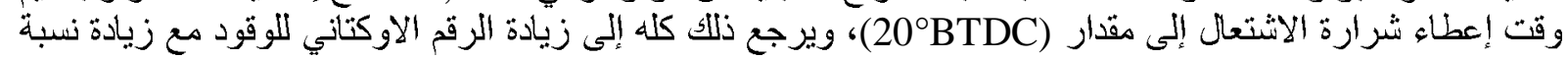

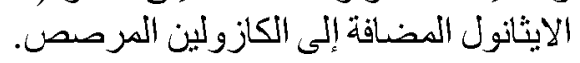

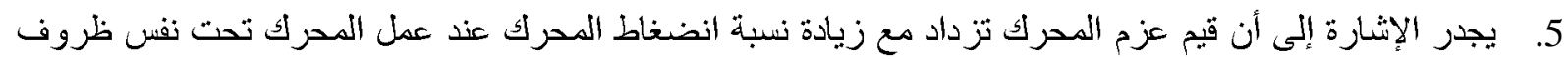

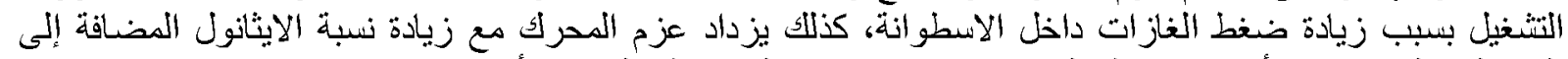

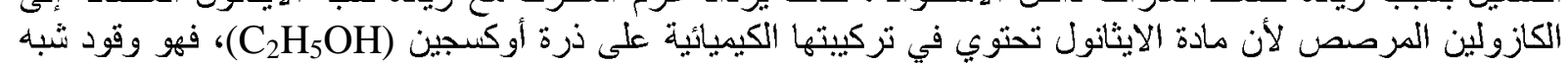


مؤكسد، ونسبة الأوكسجين فيه تساعد على تحسين عملية الاحتر اق داخل الأسطوانة، وبذللك يرتقع ضغط الغاز اتلات داخلها

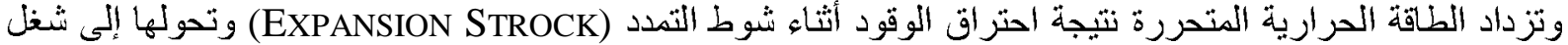

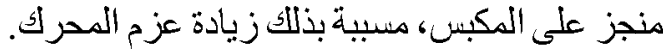
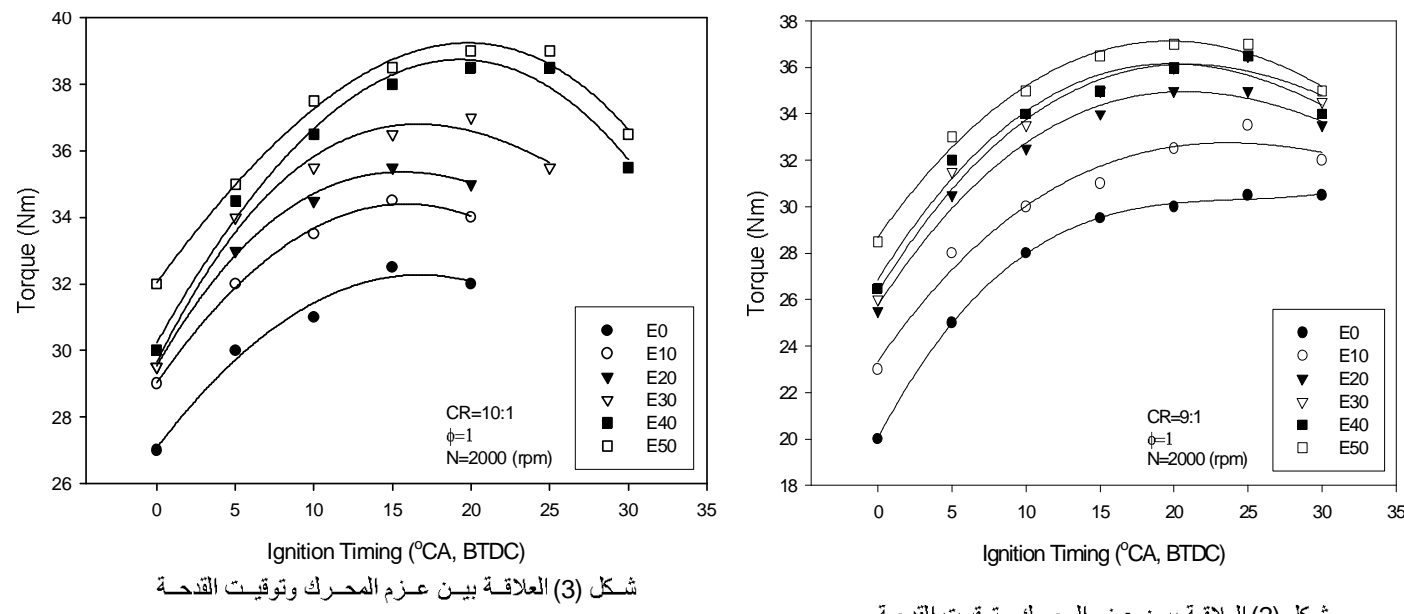

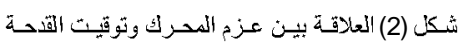

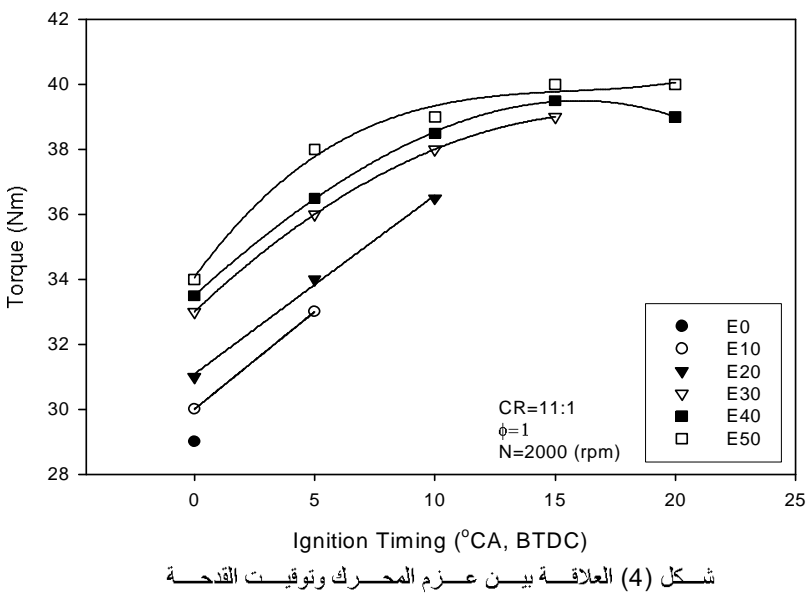

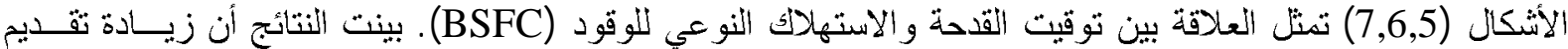

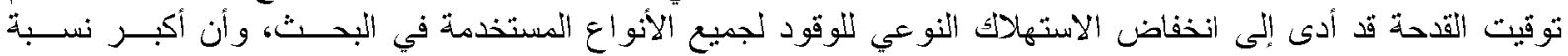

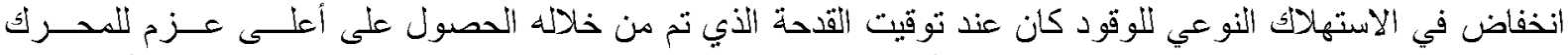

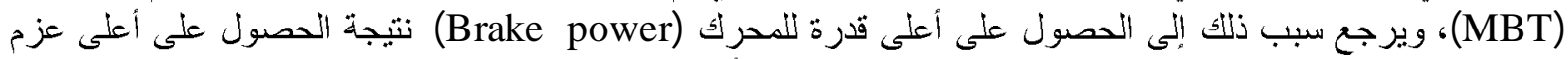

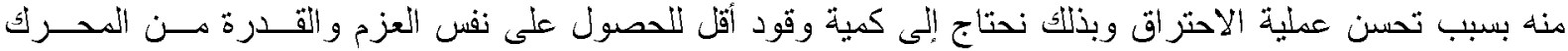
حسبما توضده المعادلات الرياضية التألية:

$P b=\frac{2 \pi N T}{60 \times 10^{3}}=(\quad) k w$

$\dot{m} f=\frac{16(\mathrm{ml}) \times S g_{f} \times 10^{-3} \times 3600}{t}=(\quad) \mathrm{kg} / \mathrm{h}$

$B S F C=\frac{m f \times 10^{3}}{P b}=(\quad) g / k w h$.

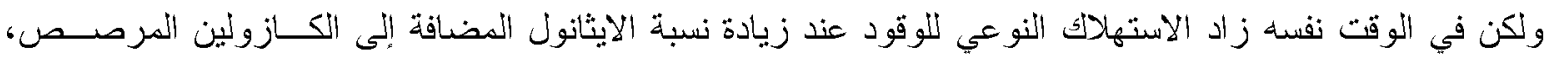

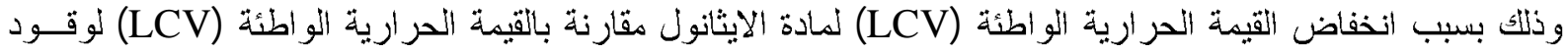

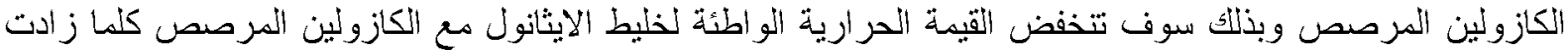


نسبة الايثانول في هذا الخليط. وللتعويض عن هذا الانخفاض في القيمة الحر ارية الو اطنئة زاد الاستهلاك النوعي للوقود

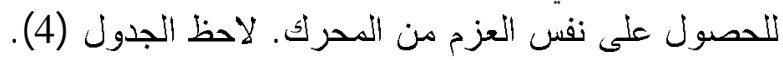
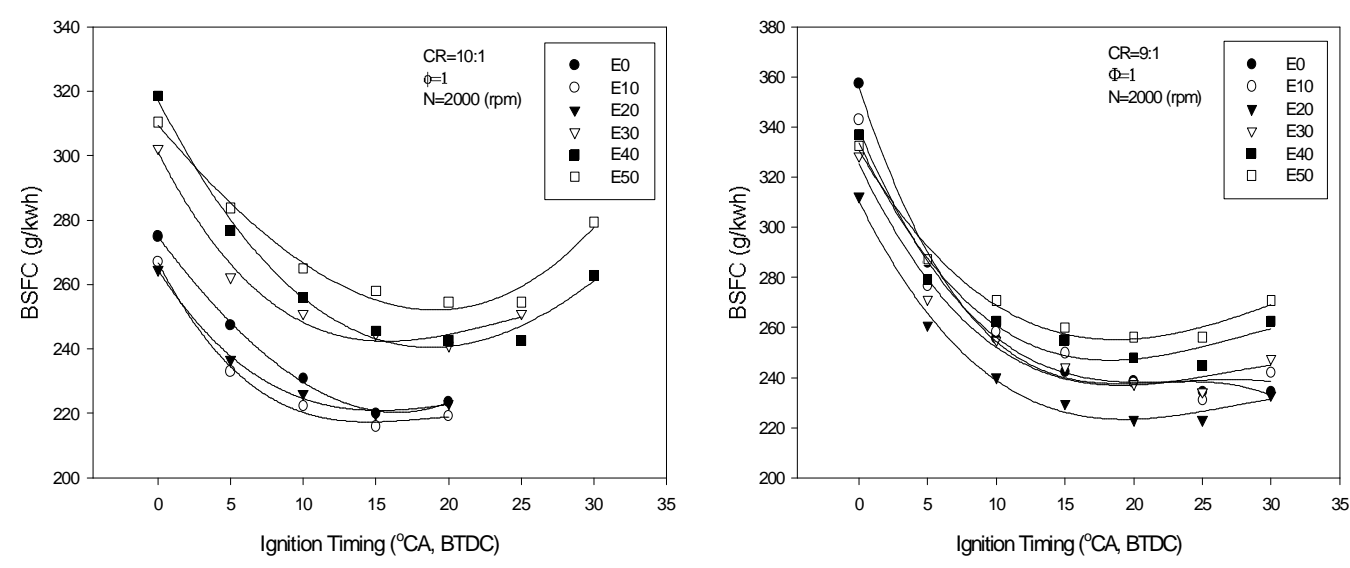

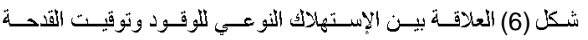
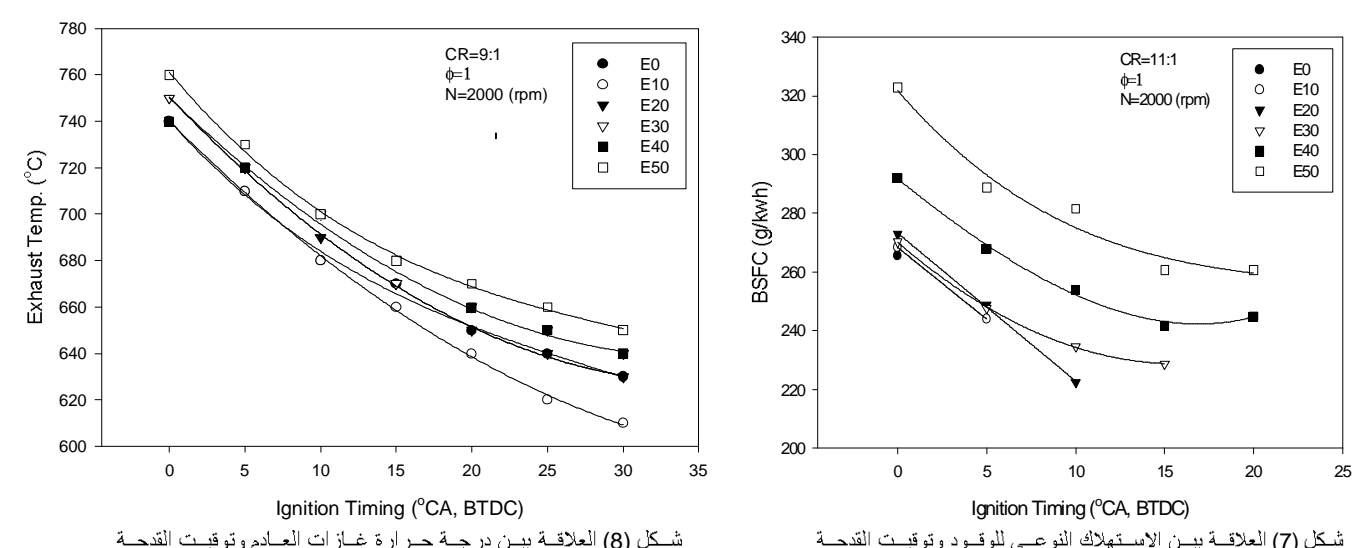

ولمعرفة علاقة درجة حرارة غاز ات العادم الخارجة هن المحرك مع توقيث القدحة تعطينا الأشكال (10,9,8)

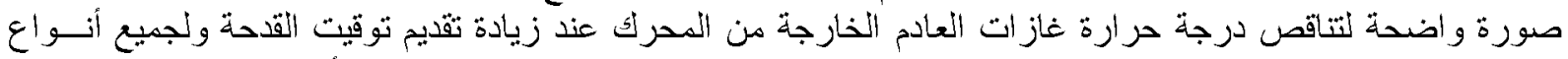

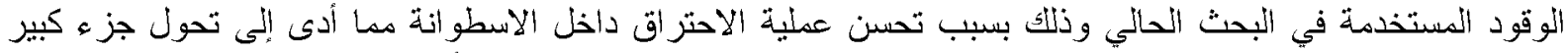

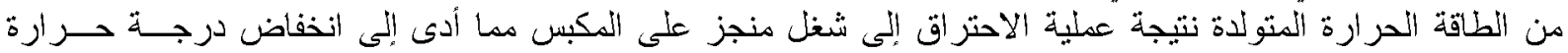

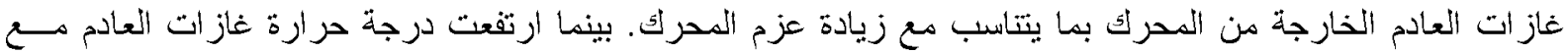

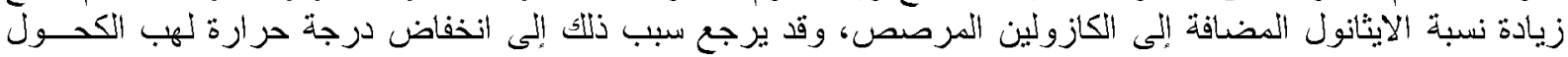

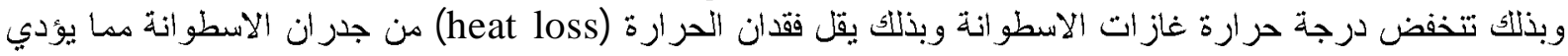
إلى ارتفاع درجة حرارة غاز ات العادم عند استخدام نسب مختلفة لإضافة الإيثانول إلى الكازولين الكرصص.
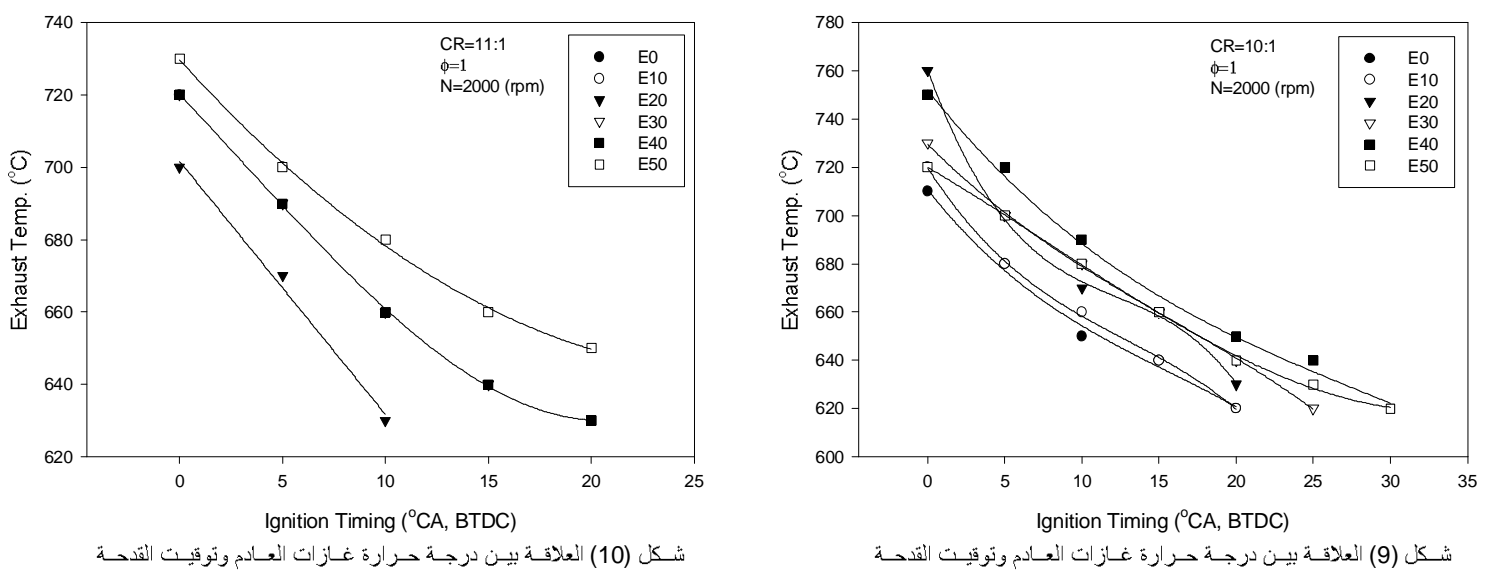
نلاحظ من خلال الأشكال (13,12,11 التي تمثل العلاقة بين نسبة انبعاث غاز أون أوكسيد الكاربون (CO)

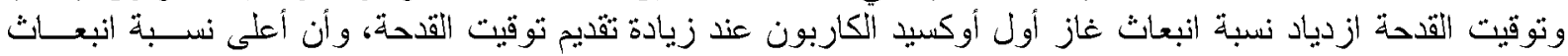

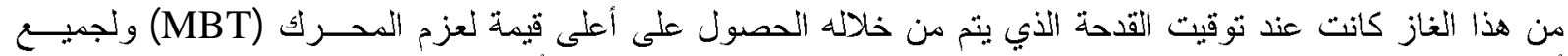

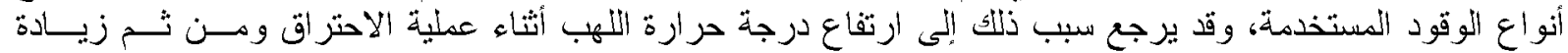

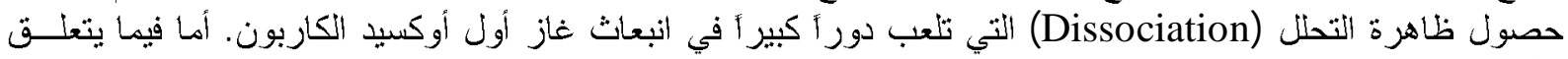

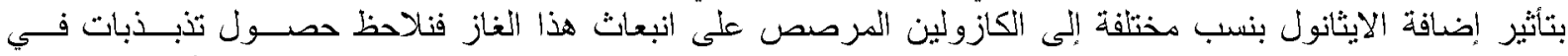

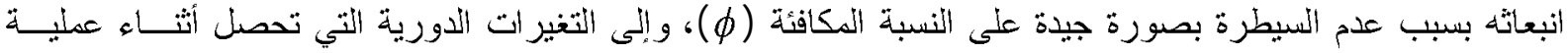

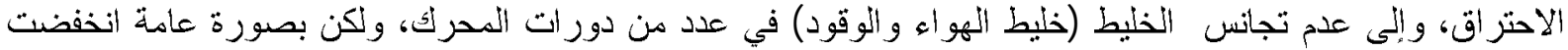

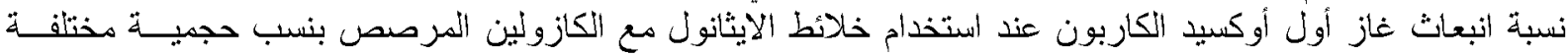

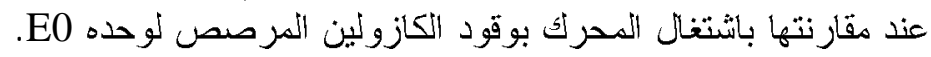

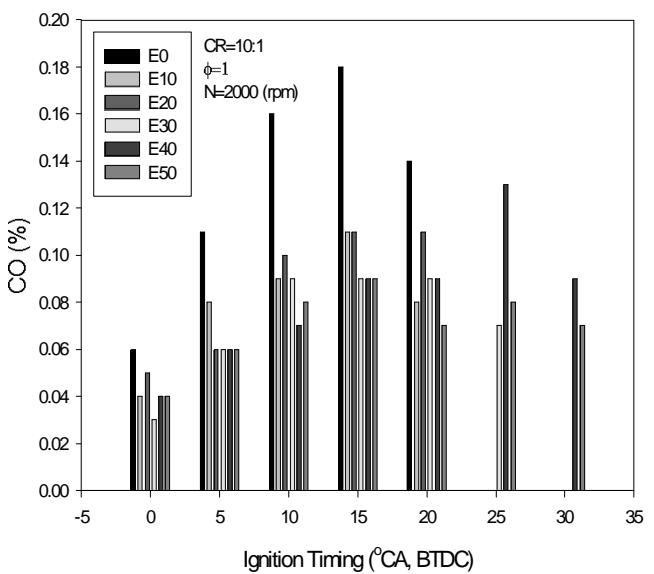

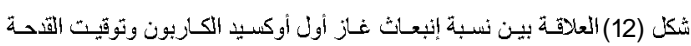

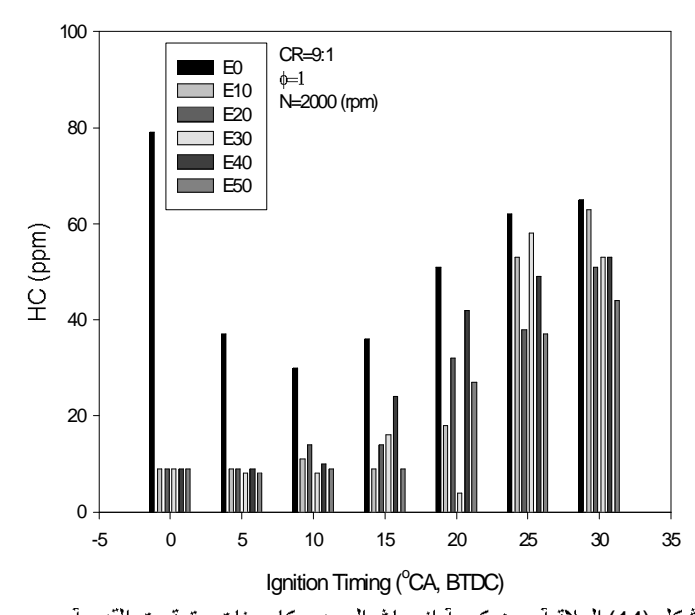

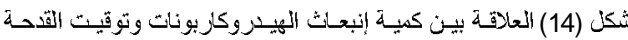

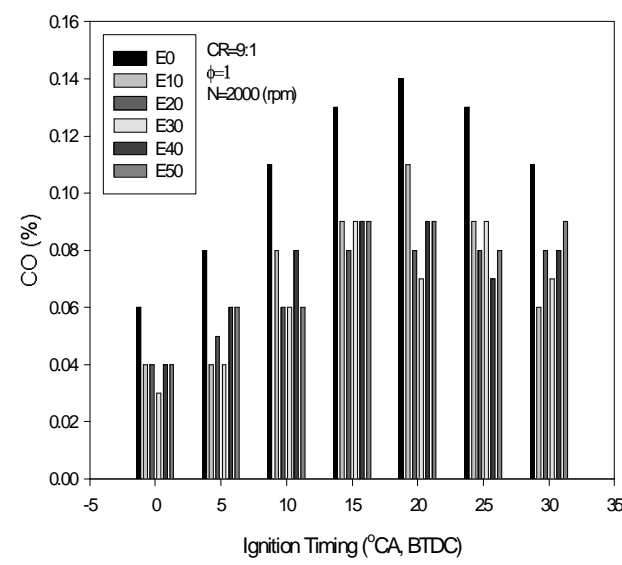

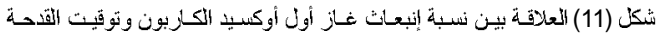

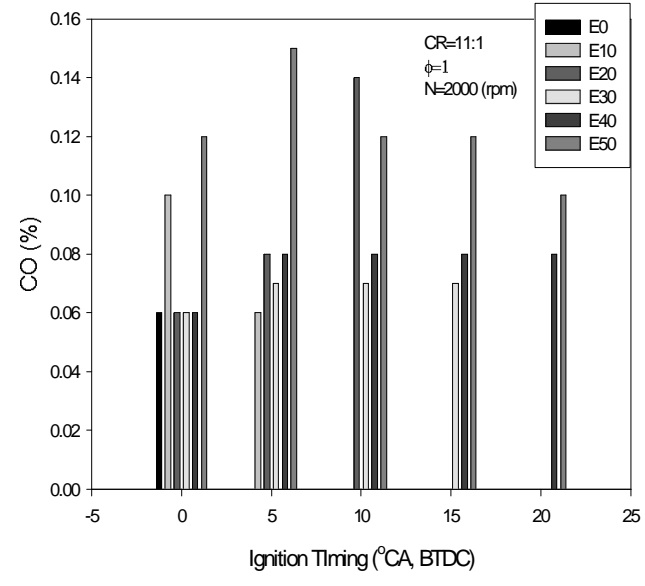

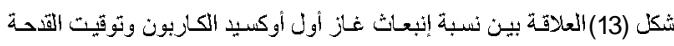

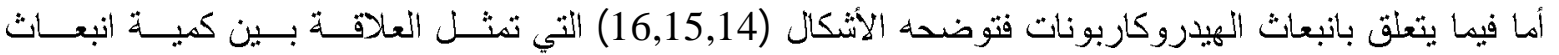

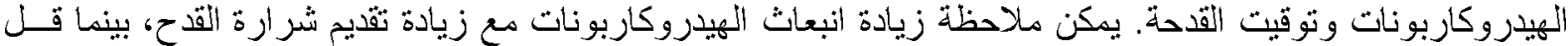

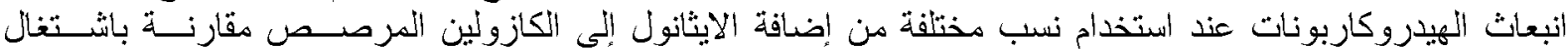

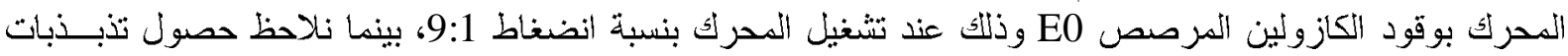
في انبعاث الهيدروكاربونات عند تتغيل انضغاط

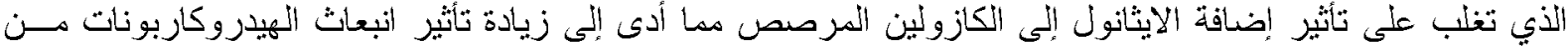

الأخاديد و التجاويف داخل غرفة الاحتر اق (Crevices volume) 


\begin{tabular}{llll} 
Al-Rafidain Engineering & Vol.18 & No.4 & August 2010 \\
\hline
\end{tabular}
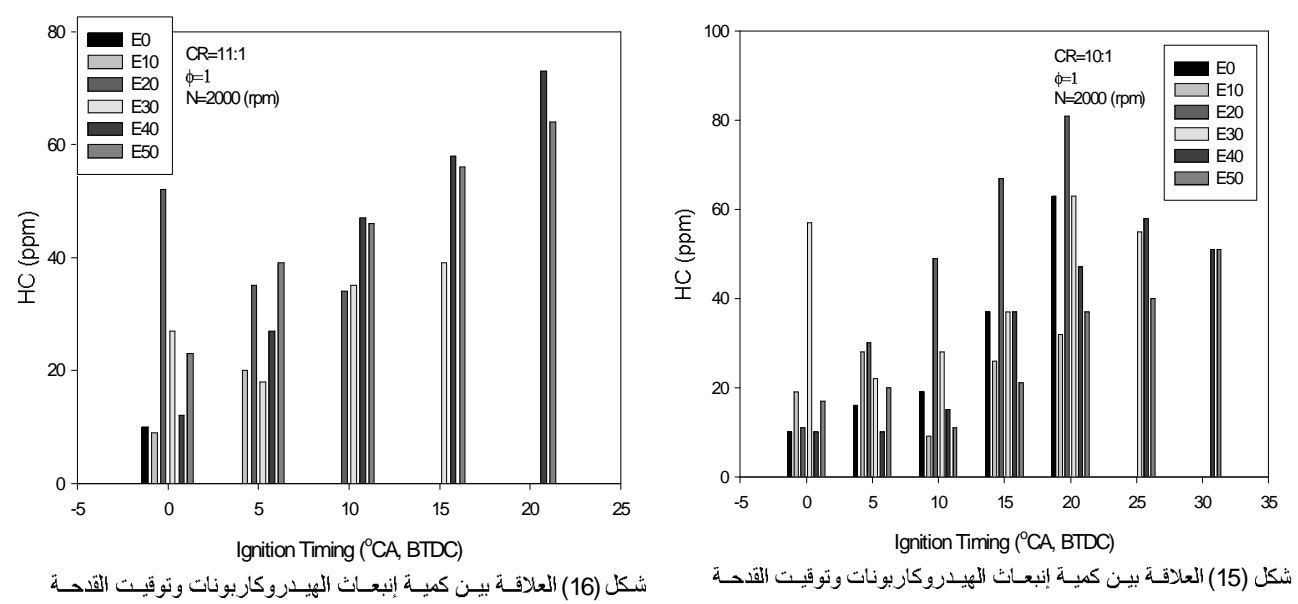

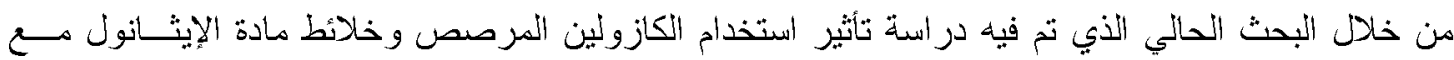

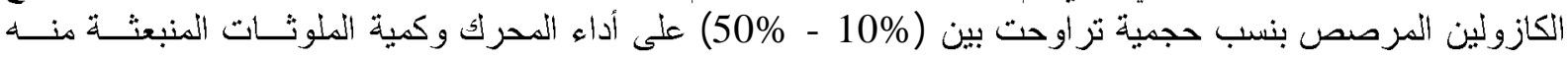

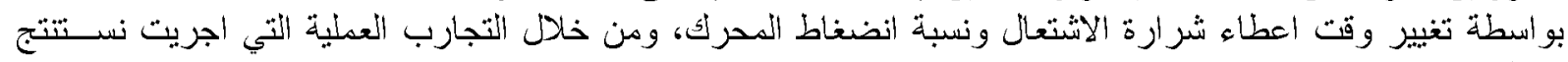
ما يلي: - اليطة تينير

1 - إن عزم المحرك يزداد مع تقديم نوقيت شر ارة القدح بصورة ملفوسة، وعند جميع نسب الانضغاط.

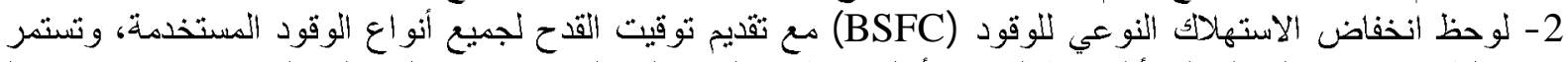

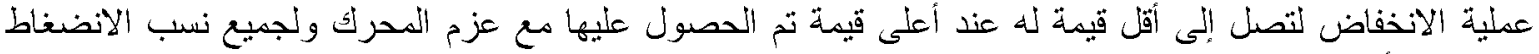
ومن ثم تبدأ بالازدياد تدريجياً.

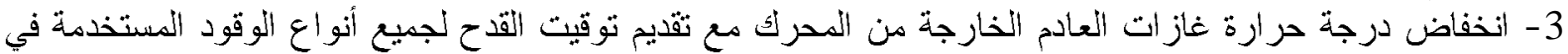

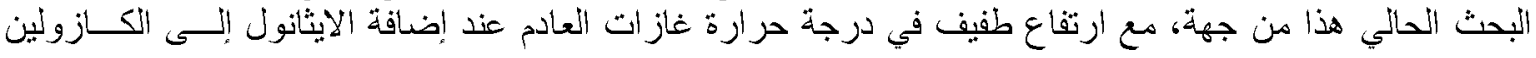
بنسب تجاوزت 30\%

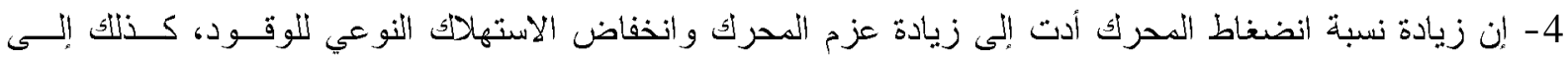

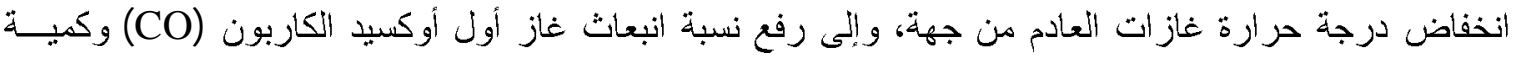

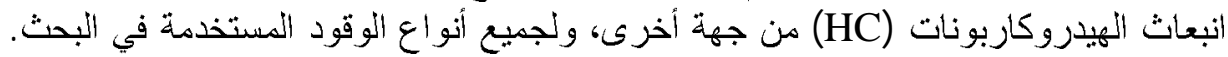

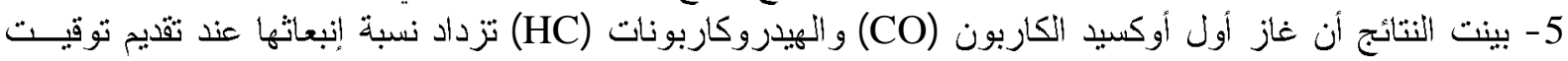
شرارة القدح.

1. M. Al-Hasan, "Effect of ethanol-unleaded gasoline blends on engine performance and exhaust emission", Transaction of PERGAMON, journal of Energy conversion and management, vol. 44, P.P. 1547-1561, 2003.

2. Maher A.R. Sadiq Al-BAGHDADI, "A simulation model for a single cylinder four-stroke spark ignition engine fueled with alternative fuels" Transaction of TUBITAK, Journal, vol. 30, PP. 331-350, 2006.

3. E. ZERVAS, X. MONTAGNE, AND J. LAHAYE, "Emissions of regulated pollutants from a spark ignition engine. Influence of fuel and air/fuel equivalence ratio", Journal of environmental science \& technology, vol. 37, No. 14, PP. 3232-3238, 2003.

4. Hüseyin Serdar Yücesu, Tolga Topgül, Can Cinar, Melih Okur, "Effect of ethanol-gasoline blends on engine performance and exhaust emissions in different compression ratios", 
Transaction of ELSEVIER, Journal of applied thermal engineering, vol. 26, PP. 2272-2278, 2006.

5. M.A. Ceviz, F. Yüksel, "Effects of ethanol-unleaded gasoline blends on cyclic variability and emissions in an SI engine", Transaction of ELSEVIER, Journal of applied thermal engineering, vol. 25, PP. 917-925, 2005.

6. Tolga, Topgül, Hüseyin Serdar Yücesu, Can Cinar, Atilla Koca, "The effects of ethanolunleaded gasoline blends and ignition timing on engine performance and exhaust emissions", Transaction of ELSEVIER, Journal of Renewable energy, vol. 31, PP. 25342542, 2006.

7. Hukan Bayraktar, "Experimental and theoretical investigation of using gasoline-ethanol blends in spark ignition engines", Transaction of ELSEVIER, Journal of Renewable energy, vol. 30. PP. 1733-1747, 2005.

8. H. Serdar Yücecu, Adnan Sonzen, Tolga Topgül, Erol Arcaklioglu, "Comparative study of mathematical and experimental analysis of spark ignition engine performance used ethanolgasoline blends fuel", Transaction of ELSEVIER, Journal of applied thermal engineering, vol. 27, PP. 358-368, 2007.

9. Fikret Yüksel, Bedri Yüksel, "The use of ethanol-gasoline blend as a fuel in an SI engine", Transaction of ELSVIER, Journal of renewable energy, vol. 29, PP. 1181-1191, 2004. 